\title{
Analysis of Johne's disease ELISA status and associated performance parameters in Irish dairy cows
}

\author{
A. E. Kennedy ${ }^{1,2}$, N. Byrne ${ }^{1}$, A. B. Garcia', J. O'Mahony ${ }^{2}$ and R. G. Sayers ${ }^{1 *}$
}

\begin{abstract}
Background: Infection with Mycobacterium avium subspecies paratuberculosis (MAP) has been associated with reductions in milk production in dairy cows and sub optimal fertility. The aim of this study was to highlight the production losses associated with testing MAP ELISA positive in Irish dairy cows. Secondary objectives included investigation of risk factors associated with testing MAP ELISA positive. A survey of management practices on study farms was also conducted, with examination of associations between management practices and herd MAP status. Blood samples were collected from 4188 breeding animals on 22 farms. Samples were ELISA tested using the ID Screen Paratuberculosis Indirect Screening Test. Production parameters examined included milk yield, milk fat, milk protein, somatic cell count, and calving interval. The association between MAP ELISA status and production data was investigated using multi-level mixed models. Logistic regression was used to identify risk factors for testing JD blood ELISA positive at individual cow level and to identify associations between farm management practices and herd MAP status.

Results: Data were available for 3528 cows. The apparent prevalence recorded was 7.4\%. Mixed model analysis revealed no statistically significant association between testing MAP ELISA positive and dairy cow production parameters. Risk factors associated with testing positive included larger sized herds being over twice more likely to test positive than smaller herds (OR $2.4 P=<0.001)$. Friesians were less likely to test positive relative to other breeds. A number of study farmers were engaged in management practices that have previously been identified as high risk for MAP transmission e.g., $73.1 \%$ pooled colostrum and $84.6 \%$ of study farmers used the calving area to house sick animals throughout the year. No significant associations however, were identified between farm management practices and herd MAP status.

Conclusion: No production losses were identified; however an apparent prevalence of $7.4 \%$ was recorded. With the abolition of EU milk quotas herd size in Ireland is expanding, as herds included in this study were larger than the national average, results may be indicative of future JD levels if no JD control programmes are implemented to minimise transmission.
\end{abstract}

Keywords: Johne's disease, ELISA, Dairy cow, Production

\section{Background}

Clinical and sub-clinical manifestations of disease can result in reductions in animal productivity leading to reduced farm profits $[1,2]$. Cost-benefit analyses are often conducted to highlight these economic losses in order to promote the use of disease control schemes [3]. Johne's disease (JD) is a chronic granulomatous enteritis of

\footnotetext{
* Correspondence: riona.sayers@teagasc.ie

${ }^{1}$ Animal \& Bioscience Research Department, Animal \& Grassland Research and Innovation Centre, Teagasc, Moorepark, Fermoy, Co. Cork, Ireland Full list of author information is available at the end of the article
}

ruminants and is caused by the bacterium Mycobacterium avium subspecies paratuberculosis (MAP) [4]. Infection with MAP has been associated with production losses at farm level although equivocal results are reported [5]. Due to a prolonged subclinical phase, variable disease progression and immune response [6], diagnosis of MAP infection is challenging. Enzyme linked immunosorbant assay (ELISA), is a popular method of testing for MAP due to its speed and low cost [7]. Despite variable sensitivity and specificity $[8,9]$, ELISA testing is often the method of choice for epidemiological studies and herd-based diagnosis [10], and forms the basis of a number of international 
control programmes [11]. It is also a common diagnostic tool used in economic studies of Johne's [5].

Economic losses reported due to infection with MAP include decreased slaughter value [12], reductions in milk production in dairy cows $[2,13]$, sub-optimal fertility [14], and an increase in cow replacement costs [15]. Although losses in clinically affected animals are well defined $[15,16]$, losses due to subclinical infection appear less well characterised [5]. An association between subclinical MAP infection and decreased milk yield (MY) has been identified in a number of studies [17-19]. In contrast a number of additional studies have identified no such association [20-22]. Similarly, conflicting reports exist regarding an association between subclinical MAP infection and milk fat (MF) or milk protein (MP) content $[17,21,23]$. An increased interval from calving to conception in ELISA positive cows has also been reported [14] in contrast to a different study showing ELISA positive cows to have fewer non-pregnant days [23]. Similarly, JE Lombard, FB Garry, BJ McCluskey and BA Wagner [23] recorded no association between MAP ELISA positivity and somatic cell count (SCC) which again conflicts with other studies [20,24] that reported an associated increase in SCC in MAP ELISA positive dairy cows.

The variability that exists across diagnostic test methods may, in part, explain the conflicting performance-related data reported across various studies [5, 25]. Geographical location, choice of sample matrix, size of study population, cow breeds, and positive cow classification also differs across studies. Serum samples were used for diagnostic purposes in some studies [22, 23], while others used individual milk samples [19]. MG Gonda, YM Chang, GE Shook, MT Collins and BW Kirkpatrick [18] defined a JD positive cow on the basis of serum ELISA and/or faecal culture results. Study sample sizes ranged from less than 1000 [22] to 35,591 dairy cows [19] with other studies only examining a single cow breed $[18,22]$. In this regard, it is important that data continue to be generated on similar cow populations, using similar study designs to improve the degree of confidence that exists in the likely impact on production in MAP positive dairy cows.

The prevalence of JD is believed to be increasing in the Republic of Ireland over the last 10 years [26]. In order to prevent further increases in MAP infection, improvements in control are required on Irish dairy farms. Although a previous Irish study [22] identified no significant effect of MAP sero-status on herd performance in 2004-2005, the increasing prevalence of MAP may now be impacting on Irish dairy production. The dairy landscape in Europe is changing due to the abolition of EU milk quotas in 2015 [27] and Irish farmers have been expanding herds over the past number of years [28]. Given Ireland's increasing herd size, a known risk factor for testing MAP positive [29], this study aimed to investigate the current impact of MAP ELISA sero-positivity on individual cow milk production, SCC and calving interval. Secondary objectives included investigation of risk factors (e.g., breed, parity, calf and calving management) associated with testing MAP ELISA positive in Irish dairy herds and investigating the strength of correlation between milk and serum ELISA results.

\section{Methods}

\section{Study population and sampling}

Blood samples were collected from all breeding animals aged over 2 years on 22 Irish dairy farms in 2012. This was conducted under licence from the Department of Health and Children, the licencing authority in Ireland at the time of the study. The location of study herds is included in Fig. 1. All but two herds were located in the dairy dense province of Munster, Ireland (south-western region) with an additional herd in each of Ulster and Leinster. A milk sample was also collected from each cow blood sampled on 17 of these farms. All study animals were observed by a veterinary surgeon during sampling visits and none displayed overt clinical signs of JD.

\section{Sample testing}

Serum and milk samples were tested by a commercial ISO accredited laboratory (Enfer Labs, Kildare, Ireland) using the ID Screen Paratuberculosis Indirect Screening Test (ID Vet, Montpellier, France). This ELISA has a reported sensitivity (Se) of $41.5 \%$ and specificity (Sp) of 99.42 [30]. The test is an M. phlei absorbed ELISA detecting anti-MAP immunoglobulin G (IgG). This ELISA was chosen as it is approved for use in Ireland's national voluntary JD pilot control programme ${ }^{1}$ and displayed the highest overall accuracy of four commercial ELISA kits investigated by ROC analysis [30]. Results were reported as sample to positive ratio ( $\mathrm{S} / \mathrm{P}$ ratio) calculated using the formula $\mathrm{S} / \mathrm{P}$ ratio $=((\mathrm{OD}$ sample $\mathrm{OD}$ Positive control $) \div(\mathrm{OD}$ Positive control - OD Negative control $) \times 100$ ). Animals were assigned MAP status (positive or negative) according to kit manufacturer interpretation ('kit-interpretation'), with serum results of $\mathrm{S} / \mathrm{P} \geq 70 \%$ classified as positive. A more severe test interpretation was also applied to blood ELISA results only in order to achieve increased test sensitivity, similar to the revised ELISA cut-off used by MT Collins, SJ Wells, KR Petrini, JE Collins, RD Schultz and RH Whitlock [31]. In this current study, instead of arbitrarily choosing a more sensitive positive cut-off, the mean $\mathrm{S} / \mathrm{P}$ ratio of cows classified as negative using kit interpretation plus three times the standard deviation was used. This yielded a new 'severe interpretation' positive cut off of $\mathrm{S} / \mathrm{P} \geq 51.59$. 


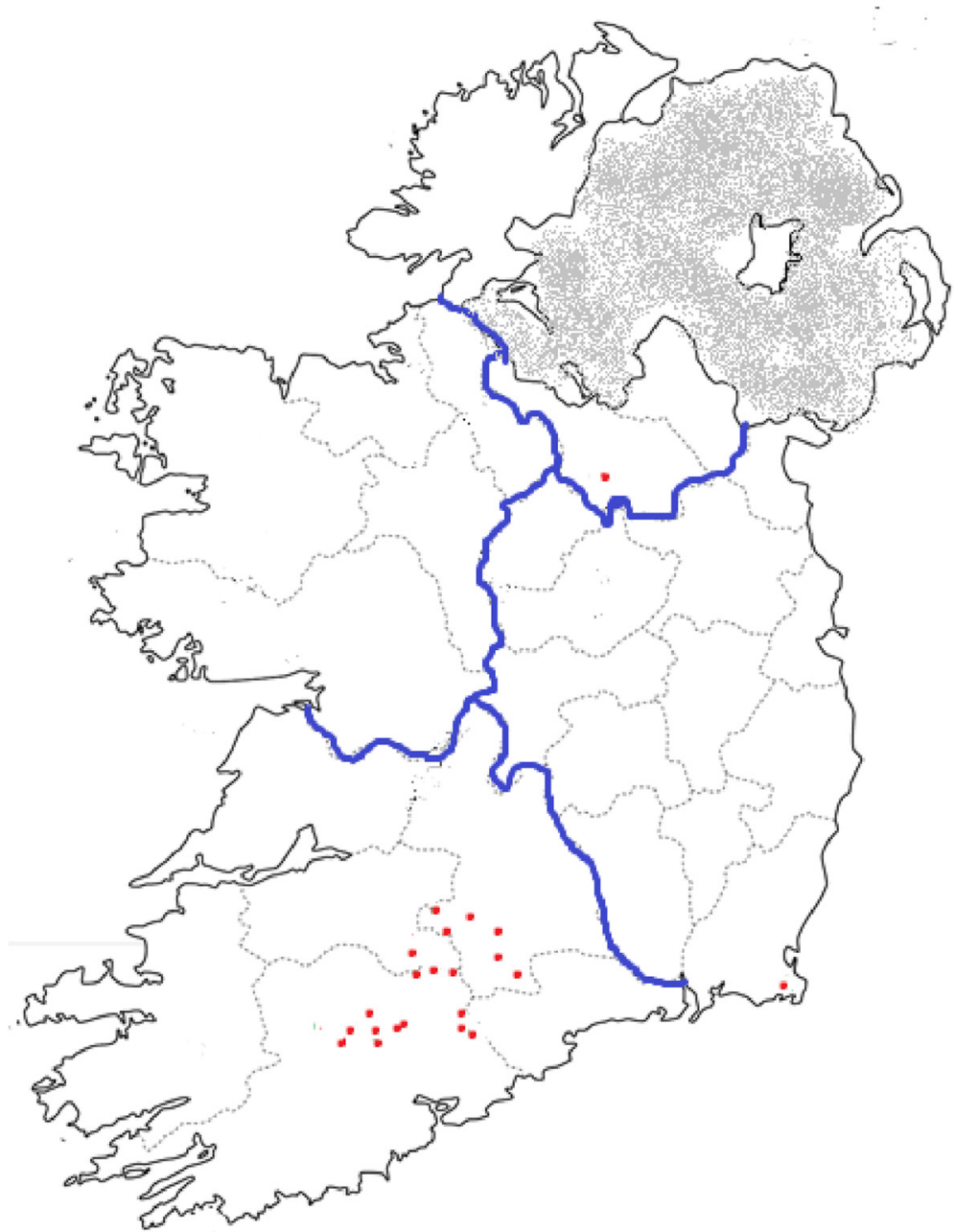

Fig. 1 Map showing location of study farms. The majority of study farms were located in the dairy dense province of Munster, with one farm located in Leinster and Ulster

\section{Individual cow performance data}

Production data for each individual cow were downloaded from the Irish Cattle Breeding Federation (ICBF) database. This database holds production data on milk recording herds to support breeding decisions and enhance genetic gain in Irish dairy herds. Production parameters downloaded included 305 day [32] MY, MF, MP, SCC, and calving interval (CI). Only calving intervals of greater than 250 and less than 500 days were retained for analysis to allow comparison with K Hoogendam, E Richardson and JF Mee [22]. Additional cow related data downloaded from the ICBF database included parity, breed, and economic breeding index (EBI; a profit index measured in Euro, aimed at identifying the most profitable cows for breeding dairy herd replacements [33]).

\section{Survey data}

Data relating to farm management practices on study farms were collected during scheduled farm visits.
Questions focused on management practices which have previously been identified in the literature as being associated with a high risk of MAP transmission.

\section{Dataset construction}

The production performance for each cow was matched to her ELISA result to create the dataset of statistical analysis. Both milk and blood ELISA results were included where available and the 'kit-interpretation' used to classify cows as positive and negative. A further dataset was constructed in an effort to identify production losses experienced by cows recording ELISA results near the manufacturers' cut off point. This dataset was constructed using the 'severe-interpretation' ELISA positive cut-off. Both blood data sets were used for the mixed model analysis with the only 'kit-interpretation' dataset used for prevalence investigations and investigating the correlation between blood and milk ELISA results. To investigate the correlation between paired milk and 
serum ELISA results, Spearman correlation ( $r s)$ was performed on categorical results i.e., cows classified as positive or negative.

\section{Data analysis}

Data manipulation and graphical representations including box plots were completed in Excel (MS 2010). Generalised linear latent and mixed models (gllamm), logistic regression, and Spearman correlations were performed using Stata (Version 12).

\section{Prevalence calculation}

The apparent prevalence's (Ap) at animal level and within herd level were calculated as total number of test positive animals out of the total number of animals tested. To estimate the true prevalence ( $\mathrm{Tp}$ ) of positive animals, a Bayesian approach and Gibbs sampling method was applied using an online epidemiological calculator (Epitools) [34]. This calculator requires prior estimates of the true prevalence and test sensitivity and specificity, based on previous data or expert knowledge. These estimates are made as beta probability distributions, with parameters alpha and beta. Alpha and beta can be calculated provided estimates of the mode and 5 or $95 \%$ confidence limits are available from expert opinion. When the mode was between 0.5 and 1 , the 95th percentile was entered into the Beta distribution utilities calculator, and the 5 th percentile entered if between 0.5 and 1. Prior estimates for true prevalence were based on a national survey which reported a prevalence of $3.3 \%$ from a study population of 15,558 animals aged over 2 years [26]. Beta probability distributions for ELISA Se and $\mathrm{Sp}$ were compiled based on estimates from peerreviewed literature [30, 31], expert opinion from Irish veterinary practitioners, veterinary officers, Teagasc veterinary and agricultural researchers, and a comprehensive longitudinal farm study involving ELISA screening and confirmatory testing using faecal culture and postmortem examination. The estimates and beta distributions used to determine $\mathrm{Tp}$ are outlined in Table 1 . Upper and lower confidence limits for $\mathrm{Tp}$ calculation were set at 97.5 and $2.5 \%$ respectively. Outputs reported in this study are median values of posterior distributions for prevalence, sensitivity and specificity.

\section{Associations between cow performance and MAP ELISA status}

All data were visually assessed for normality using ladder of powers histograms in Stata. The association between MAP ELISA status and production data was investigated using gllamm. Models accounted for random effects of cow nested within herd. Covariates were retained in the final multivariable models on the basis of the highest reduction in the Bayesian information criterion (BIC).
Table 1 Estimates for use in true prevalence calculation

\begin{tabular}{llll}
\hline & $\begin{array}{l}\text { Estimates of posterior } \\
\text { distributions }\end{array}$ & Beta distribution \\
\cline { 3 - 4 } & & Alpha & Beta \\
\hline Animal & $0.033(0.072)^{a}$ & 5.2021 & 124.1336 \\
Prevalence & $0.41(0.587)^{a}$ & & \\
Sensitivity & $0.99(0.47)^{a}$ & 9.9689 & 13.5179 \\
Specificity & & 4.0322 & 1.0306 \\
\hline
\end{tabular}

The online epidemiological calculator (Epitools) used to calculate true prevalence requires prior estimates of the true prevalence and test sensitivity and specificity, based on previous data or expert knowledge. These estimates are made as Beta probability distributions, with parameters alpha and beta. Alpha and beta can be calculated provided estimates of the mode and 5 or $95 \%$ confidence limits are available from expert opinion

Initial values represent the mode, with the value in brackets representing either the $5^{\text {th }}$ or 95 th percentile

ahen the estimated value was between 0 and 0.5 the 95 th percentile was chosen, and when the estimate was between 0.5 and 1 the 5 th percentile was chosen

Covariates examined in each model were breed (Friesian/Friesian crosses (FRx), Jersey/Jersey crosses (JEx), Norwegian Red/Norwegian Red crosses (Redx), other), parity $(1,2,3,4,5,6,7,8,9, \geq 10)$, EBI (categorised into quartiles, category 1 being the highest quartile and category 4 the lowest) and herd size ( $\leq 150$ cows, $>150$ cows). This number was chosen as average herd size of study herds was 153 cows. Second-level interactions between covariates were also examined. Values of $P<0.05$ were considered significant.

\section{Associations between breed, herd size, parity, EBI and MAP ELISA status}

Logistic regression was used to identify risk factors for testing MAP blood ELISA positive at individual cow level (dependent variable). Independent variables examined in regression included breed, herd size, parity and EBI. These variables were coded as described for gllamm models. Herd of origin was forced into all models. A manual backwards elimination with a forward step was performed for each model. Interactions between variables were also examined. Variables recording a significance level of $P<0.05$ were retained in the model and are reported.

\section{Associations between farm management practices and herd MAP status}

Logistic regression was used to identify associations between testing MAP blood ELISA positive at a herd level and farm management practices (survey responses). A herd was classified as positive if a minimum of one blood ELISA positive result was identified. Herd size was included in the model as a covariate, as larger herds are more likely to test positive [29]. Again a manual backwards elimination was performed with interactions between variables examined. Variables recording $P<0.05$ were considered significant. 


\section{Results}

\section{Descriptive data}

Samples were collected from 4188 breeding animals. Production data were available for 3528 dairy cows, the remainder $(n=660)$ being excluded from further analysis. These exclusions consisted of misidentified animals, breeding bulls, and beef cows in herds having mixed beef and dairy enterprises. Of the 22 herds, nine contained $>150$ cows.

The predominant breed sampled was FRx (82.7\%), the remaining 10.3, 5.5 and $1.5 \%$ being Redx, Jersey, and other, respectively (Fig. 2). The majority of animals tested were parity1 (30.1\%) or parity 2 (26.4\%) (Fig. 3).

\section{Prevalence}

The highest within herd Ap recorded on any single farm was $56 \%$. Box plots showing range of $\mathrm{S} / \mathrm{P}$ ratios across all herds with at least one positive animal are shown in Fig. 4. The overall study Ap recorded utilising blood MAP ELISA was $7.4 \%$. Based on the Bayesian analysis, Tp was estimated at $3.8 \%$, with a median output test Se and Sp of 41.6 and $94 \%$, respectively. All cows tested in three herds recorded negative blood MAP ELISA results and these herds contained $<150$ cows. A breakdown of the positives across parity, breed, and herd size are outlined in Table 2. The highest proportion of animals testing ELISA positive were third parity and Redx being proportionally the predominant breed testing positive (Figs. 5 and 6, respectively), although the majority of Redx testing positive were from a single herd. Many of the animals testing positive in this herd were born in the same year.

\section{Milk ELISA results}

A total of 131 from 1696 cows available for analysis, tested milk ELISA positive for MAP. Of these, 61 also tested positive on blood. The remaining 70 animals recording positive milk ELISA results tested negative on blood ELISA. It should be noted that samples from 47 'milk positive blood negative' cows were collected in September/October/November. These samples would therefore have been collected during late lactation in the Irish Spring calving dairy system. Further to this a number of the blood results, although classified as negative, were approaching the manufacturer cut off point of $70 \mathrm{~S} / \mathrm{P}$, possibly explaining the discrepancy between milk and blood ELISA. Spearman correlation yielded a $\rho$ value of 0.19 indicating poor correlation between milk and blood test results at a categorical level (Fig. 7).

\section{Management practices- survey}

The majority (73.1\%) of respondents purchased animals onto their farms. Approximately, three quarters of study farmers fed calves pooled colostrum (73.1\%) and pooled milk (76.9\%). Additionally, milk not fit for sale i.e., milk containing antibiotic residues or milk from sick/mastitic cows was used to feed calves on $65.2 \%$ of study farms. Group calving pens were used by $54 \%$ of study farmers. The majority $(84.6 \%)$ of study farmers also used the calving area to house sick animals throughout the year. A high proportion of farmers removed calves from the

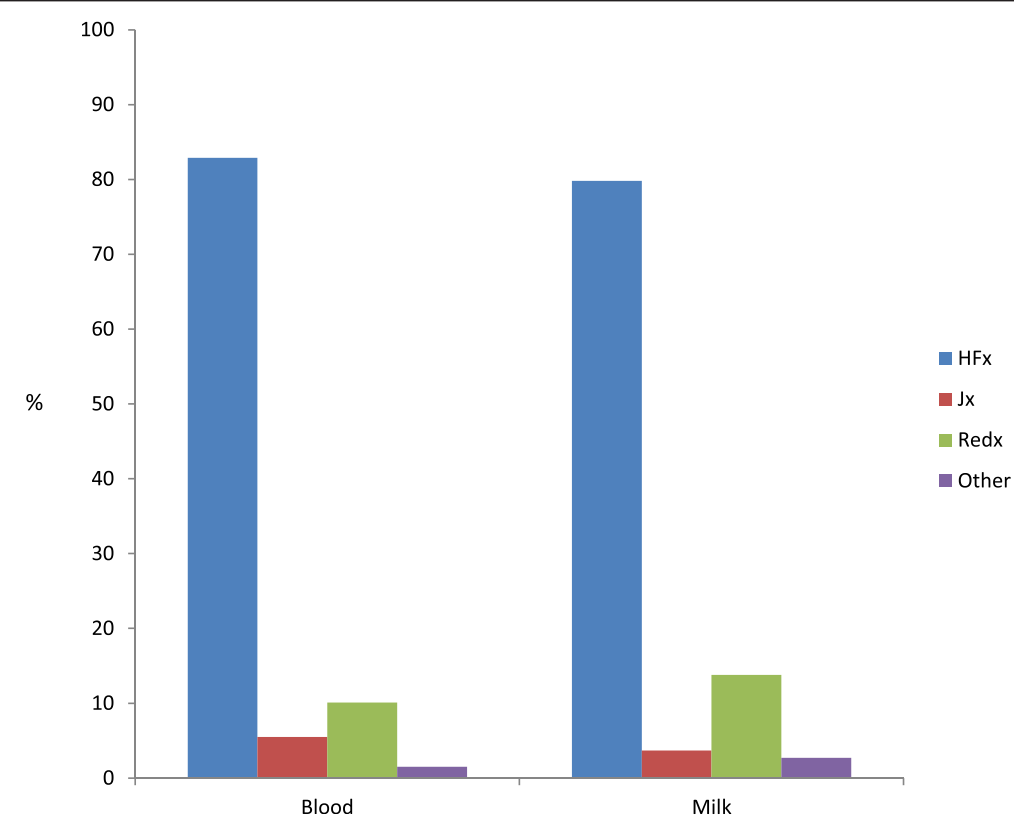

Fig. 2 Proportion of animals tested belonging to each breed. The predominant breed tested using both milk and blood ELISA was Friesian. HFx: Friesian, JX: Jersey, Red: Norwegian red 


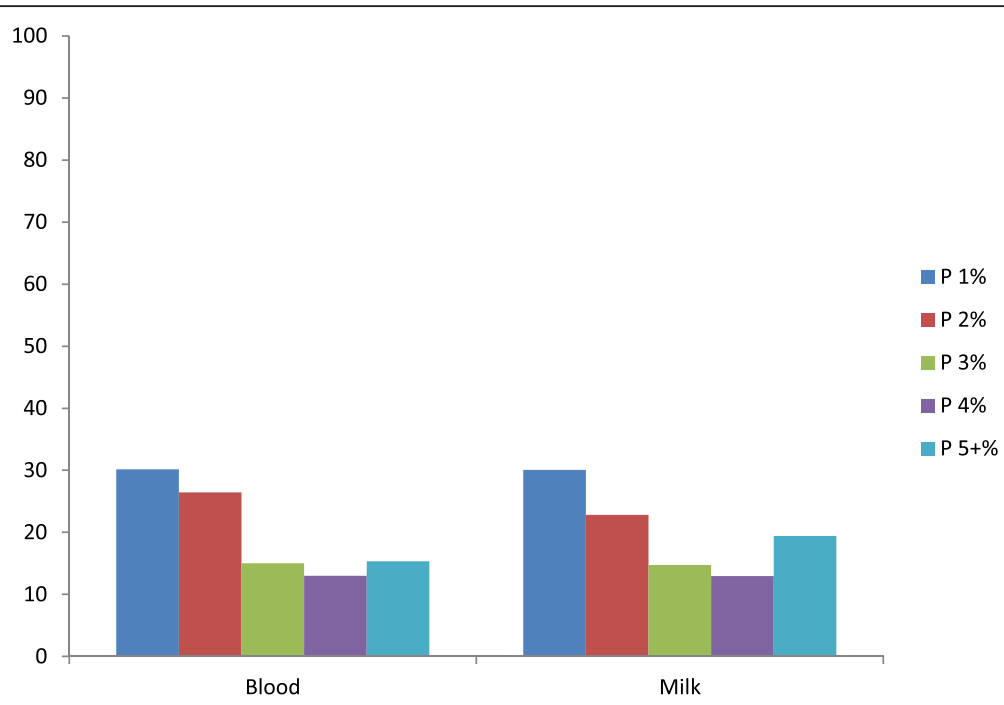

Fig. 3 Proportion of animals tested belonging to each parity. The majority of animals tested were of parity 1 or parity 2 . P = parity

calving area within 30 min of birth (65.4\%). Similarly, the majority of study farmers didn't allow calves to suckle the dam (65.4 \%) (Fig. 8).

\section{Production data}

Mean milk yield was $5494 \mathrm{kgs}$. Mean milk fat and protein was $240 \mathrm{kgs}$ and $196 \mathrm{kgs}$ respectively. As a percentage of yields this equated to $4.4 \%$ milk fat and $3.6 \%$ protein.

\section{Mixed model analysis of production parameters}

Multilevel mixed model analysis revealed no statistically significant association between testing MAP ELISA positive and MY, milk solids, CI, and SCC. Similarly, analysis of the 'severe interpretation' dataset again revealed no statistically significant differences (Table 3). No statistically significant association between testing milk ELISA positive and MY, milk solids, CI, and SCC was identified.

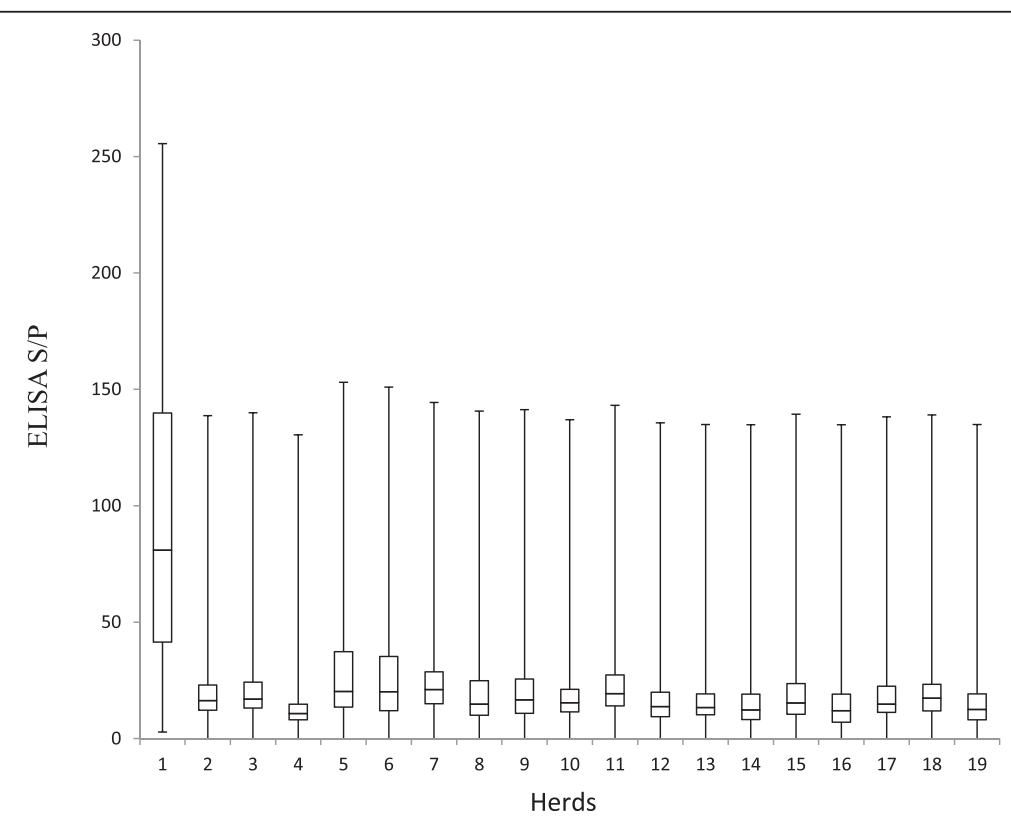

Fig. 4 Box plot showing range of S/P ratios across all herds that recorded at least one positive animal. Over half of the animals in herd 1 tested positive 
Table 2 Breakdown of positives across parity and breed

\begin{tabular}{lllllllllll}
\hline Matrix & Total tested & P 1 \% & P 2 \% & P 3 \% & P 4 \% & P 5 \% & HFX \% & Jx \% & Redx \% & Other \% \\
Blood & 3528 & 30.1 & 26.4 & 14.9 & 13 & 15.6 & 82.7 & 5.5 & 10.3 & 1.5 \\
Milk & 1686 & 30 & 22.8 & 14.7 & 13 & 19.5 & 80.5 & 3.7 & 14.1 & 1.7 \\
& Total Positive(n) & P 1 \% & P 2 \% & P 3 \% & P 4 \% & P 5 \% & HFX\% & Jx\% & Redx\% & Other\% \\
Blood & 261 & 29.5 & 28.7 & 14.2 & 10.0 & 17.6 & 53.6 & 2.4 & 39.8 & 4.2 \\
Milk & 131 & 27.5 & 16.8 & 13.7 & 13 & 29 & 56.4 & 3.9 & 32.8 & 6.9 \\
\hline
\end{tabular}

$P$ parity

\section{Associations between breed, herd size, parity, EBI and MAP ELISA status}

Statistically significant results of logistic regression analysis are included in Table 4. Larger herds were over twice more likely to test positive than smaller herds. Redx and breeds classed as other were more likely to test JD ELISA positive than FRx (OR 6.5, 5.5 respectively). No significant associations were highlighted between parity, EBI and MAP ELISA status.

\section{Associations between farm management practices and herd MAP status}

No significant association was identified between calving area, calf feeding management practices and MAP ELISA status.

\section{Discussion}

Economic losses are often reported due to JD [35]. Given Ireland's increasing herd size, a known risk factor for testing MAP positive [29], this study aimed to investigate the current impact of MAP ELISA sero-positivity on individual cow performance. Secondary objectives included investigation of risk factors (e.g., breed, parity, calf and calving management) associated with testing MAP ELISA positive in Irish dairy herds and investigating the strength of correlation between milk and serum ELISA results.

Two previous Irish reports have highlighted significant losses in JD clinically affected animals $[13,16]$, but are limited to individual farm case studies as opposed to across farm studies. An additional Irish study involving 34 herds, however, reported no statistical effect of JD

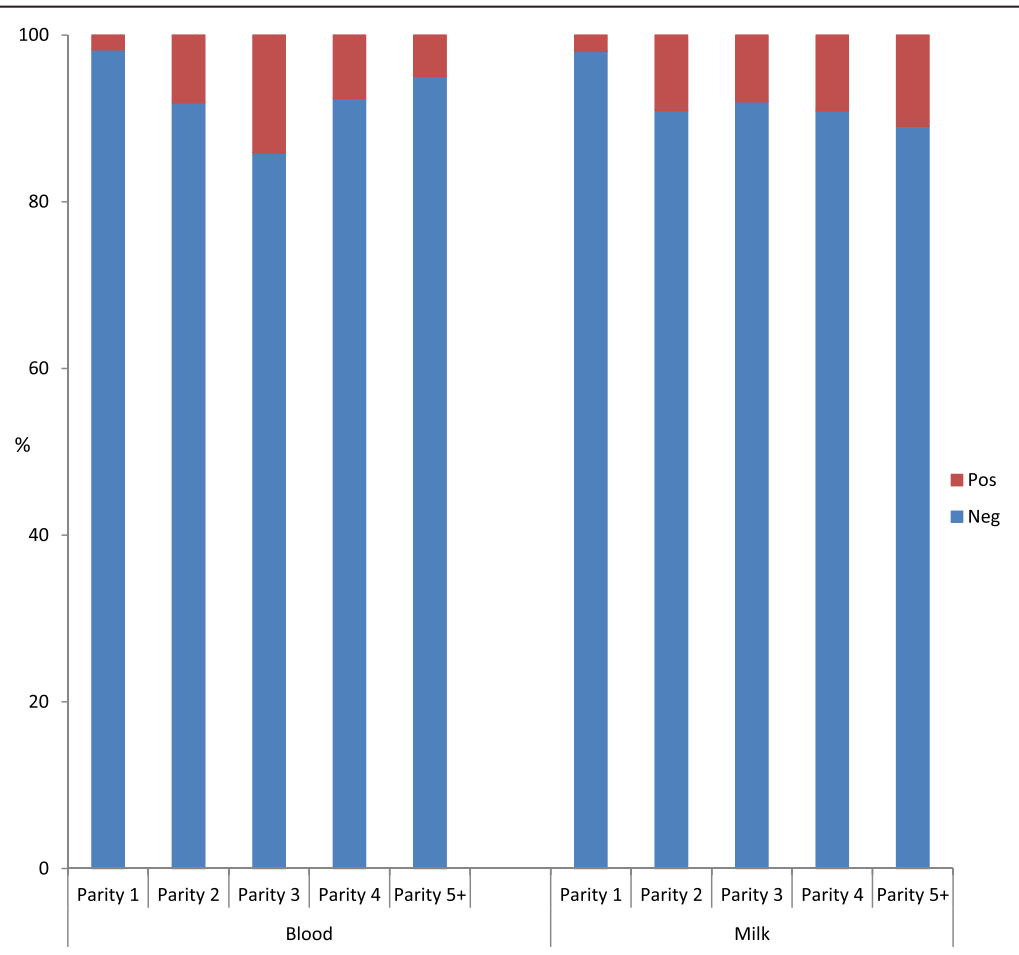

Fig. 5 Proportion of animals testing positive per parity. The highest proportions of animals testing blood ELISA positive were of parity 3 


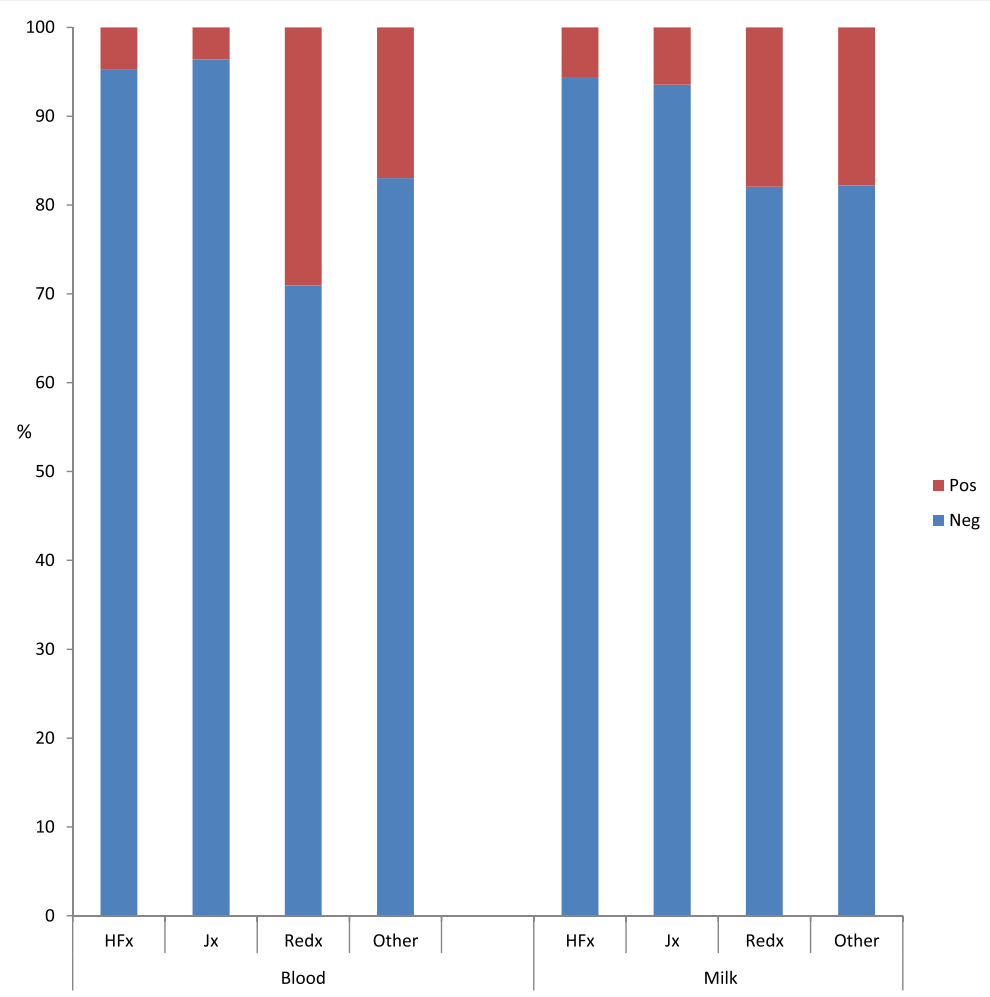

Fig. 6 Proportion of positive results recorded across each breed. Norwegian reds were proportionally the predominant breed testing positive. The majority of this breed testing positive however originated from the same herd. HFx: Friesian, JX: Jersey, Red: Norwegian red

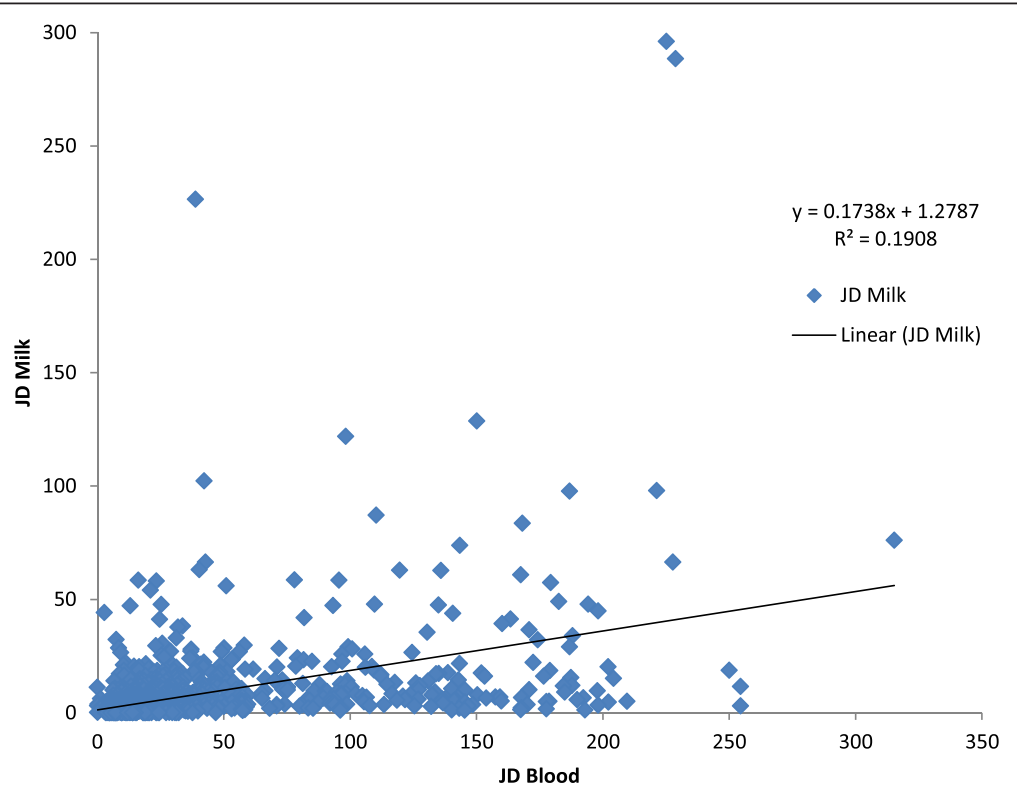

Fig. 7 Scatter plot showing the relationship between matched blood and milk samples. An $R^{2}$ value of 0.1908 was obtained 


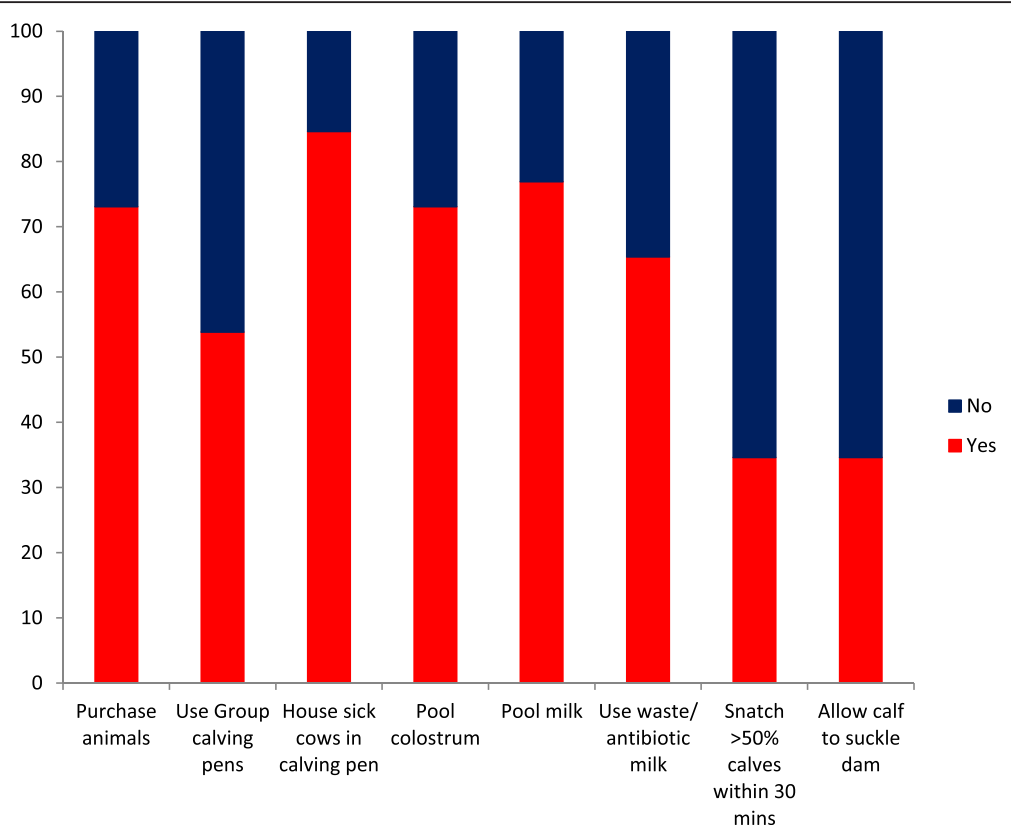

Fig. 8 Responses to survey questions. The questions focus on management practices that have previously been associated with JD transmission. The high risk practices for JD transmission are shown in red

sero-status (sub-clinical cows) on Irish dairy cow milk and fertility performance parameters [22]. As the study conducted by K Hoogendam, E Richardson and JF Mee [22]. involved a sample size of 949 and only 11 serologically positive individuals, it was necessary to conduct a larger study in Irish dairy herds. Both the overall

Table 3 Results from multilevel mixed model analysis

\begin{tabular}{llll}
\hline Dataset Name & $\begin{array}{l}\text { Coefficient: JD positive vs. JD } \\
\text { negative }\end{array}$ & $\begin{array}{l}\text { Stnd } \\
\text { Error }\end{array}$ & $\begin{array}{l}P \\
\text { Value }\end{array}$ \\
$\begin{array}{l}\text { Dependent } \\
\text { Variable }\end{array}$ & & & \\
\hline Blood & -8.7 & 47.3 & 0.854 \\
Milk Kgs & 0.14 & 0.01 & 0.424 \\
Protein \% & -0.03 & 0.03 & 0.343 \\
Fat \% & -3.2 & 2.0 & 0.098 \\
Calving Interval & 10.3 & 21.7 & 0.635 \\
SCC & & & \\
Severe & -3.91 & & \\
Interpretation & -0.01 & 52.5 & 0.9406 \\
Milk Kgs & -0.02 & 0.01 & 0.6745 \\
Protein \% & -4.52 & 0.03 & 0.5257 \\
Fat \% & 10.4 & 5.04 & 0.3695 \\
Calving Interval & 22.4 & 0.6432 \\
SCC & & &
\end{tabular}

No significant associations between production parameters and sero status were identified utilising the manufacture cut of point of 70 or the severe interpretation cut off point of 51.59

$P$ Value: Significant $P<0.05$ sample size and number of ELISA positive animals detected, were considerably higher in the current study (3528 cows and 261 positives) which would greatly increase the confidence in the findings reported. It was unexpected, therefore, that a continuing lack of statistically significant association between JD sero-positivity and performance in Irish dairy cows was highlighted. This is not particular to Ireland; with additional international studies reporting similar findings [5, 21]. It may be suggested, therefore, that use of poor sensitivity, and possibly specificity, ELISA tests as are currently available is not an ideal study design in order to detect subclinical losses due to JD infection. Studies, however, have detected losses in sero-positive individuals $[19,23]$ and as ELISA testing forms an integral part of many international control programmes [11,36], studies aimed at highlighting production losses associated with JD ELISA status are important additions to the global JD database. Further such studies may allow an analysis of geographical differences in the impact of sub-clinical JD across various countries, which in turn could assist in identifying protective or stimulatory factors with regard to JD infection.

The impact on production associated with testing MAP ELISA positive will differ depending on choice of diagnostic test. This is because the accuracy of MAP testing differs across both kits and stage of infection in the animal tested [5]. Indeed the poor correlation between the use of milk and blood samples identified in the current study serves to clearly highlight the considerable variability between diagnostic test methods, especially 
Table 4 Logistic regression- Significant associations between testing MAP ELISA positive and independent variables

\begin{tabular}{|c|c|c|c|c|}
\hline Dependent Variable & Odds Ratio & $P$ Value & Conf. Interval (95\%) & Model $^{a}$ \\
\hline \multicolumn{5}{|l|}{ Independent Variable } \\
\hline \multicolumn{5}{|l|}{ Johne's disease ELISA positive } \\
\hline Herd size & & & & Herd of originBreedHerd sizeParityEBI \\
\hline Herd size $>150$ cows vs. herd size $<150$ cows & 2.4 & $<0.001$ & $1.7,3.4$ & \\
\hline \multicolumn{5}{|l|}{ Breeds } \\
\hline Red $x$ vs. FRx & 6.5 & $<0.001$ & $4.8,8.9$ & \\
\hline Other vs. FRx & 5.5 & $<0.001$ & $2.5,12.2$ & \\
\hline Red $x$ vs. Jex & 12.2 & $<0.001$ & $5.2,28.6$ & \\
\hline Other vs. Jex & 10.3 & $<0.001$ & $3.3,32.1$ & \\
\hline
\end{tabular}

Larger sized herds were more likely to test positive compared to smaller sized herds. Friesians were less likely to test positive relative to other breeds examined

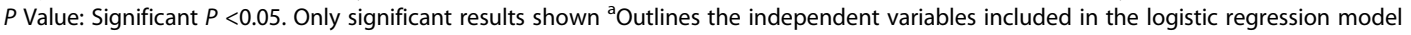

at different stages in lactation as highlighted in this study and others [37, 38]. Indeed as the specificity of MAP ELISA is not $100 \%$ [9], it is possible that a proportion of the animals identified as positive in the current study may be false positives. The Bayesian estimates of $\mathrm{Tp}$ would support this in that it indicates a lower level of true infection than the apparent prevalence recorded. Identification of false positives and false negatives due to less than optimal test sensitivity and specificity would lead to miscategorisation of individuals hence reducing the likelihood of detecting association between performance and ELISA status. This again stresses the importance of using large sample size studies for these analyses. The current study strove to correct for poor test sensitivity by using a 'severe-interpretation' yet production differences remained unidentifiable.

A number of environmental mycobacteria have been identified in Ireland [39]. Environmental mycobacteria are known to contribute to false positive ELISA results [40], potentially allowing interference with results in the current study. As faecal culture positive cows have been shown to have consistently larger effects on all production traits compared to MAP ELISA positive cows [18], a limit of this study is the lack of faecal culture. A study conducted in the same region as the current study however, showed moderate agreement between ELISA testing and culture techniques [41], indicating there is a level of agreement between ELISA and culture tests in the region. As, however, results from this study indicate no economic effect of testing ELISA positive, it may indicate that future economic investigations in Ireland should not be conducted utilising ELISA alone. It may also prove worthwhile in future studies to increase the ELISA test kit cut-off as a means of potentially improving test specificity.

It was important to identify whether farmers engaged in good Johne's management in this study to examine the influence of the farmer as a protective influence. Not only were farmers in the current study not engaging in protective practices, a higher level of adoption of certain high risk management practices than previously reported in Ireland was recorded. The current study reported $65 \%$ of study farmers feeding waste/antibiotic milk to calves compared to $59.6 \%$ in the previous national study [42]. Use of the calving area to house sick animals was also reported at a much higher level than previous national [42] and international studies [43]. Results from this study also show higher usage of group calving pens than that reported elsewhere $[41,43]$ possibly placing study farms at increased risk of the incidence of diarrhoea, including salmonella and JD [44, 45]. Indeed maintenance of a closed herd is a key element of general herd biosecurity [46] however over $70 \%$ of study farmer's reported not operating a closed herd. Given the high level of high risk management practices reported in the current study and a previous study [42] it is important to provide information to farmers about the pathogenesis and transmission of JD to minimise future JD levels. As almost all participants were utilising high risk management practices, it is perhaps unsurprising that no significant differences were identified between management practices adopted on test positive and test negative herds.

Although a high number of MAP ELISA positive animals were identified, no animal was observed to be displaying clinical signs of JD at the time of sampling. As typical results in relation to JD risk factors were identified i.e., larger herds being more likely to test positive, perhaps it indicates an unidentified element exists within Irish dairying systems that limits the production effects and clinical signs on Irish cattle. Potential protective effects may include the widespread use of grass based systems in Ireland or the lower average herd size compared to other countries $[47,48]$. It may also however relate to the level of environmental mycobacteria present and the extensive TB testing programme that operates in Ireland. Infection with MAP can lead to false positive reactions on the intradermal skin test for bTB [49]. As a bTB test 
is administered on at least a single occasion annually to every bovine in Ireland, removal of 'MAP reactors' prior to the development of clinical signs is possible, potentially explaining negligible losses.

Further to this, although the annual culling rate of approximately $21 \%$ is lower than some countries [50], this level of culling may have led to the removal of some MAP infected animals prior to the onset of clinical signs. Currently the dairying sector in Ireland and the EU in general is entering a period of change due to the abolition of EU milk quota restrictions. The Irish dairy sector has set targets to increase dairy output by $50 \%$ by 2020 (Food Harvest 2020). In order to meet this 2020 target, there is a requirement to increase cow numbers by 350,000 in Ireland by 2020, compared to average cow numbers between 2007 and 2009 [51]. With the abolition of EU milk quotas and the intent of many farms to expand in size [27], it may be that animals that would previously have been culled may in future be retained in the herd, potentially leading to an increased risk of MAP transmission. As this study involves herds larger than the national average herd size and results show an increased number of animals testing positive than previous Irish studies, it will be important to monitor the production effects associated with testing JD positive, as national herd size expands.

The greater likelihood of Redx to test positive relative to JEx and HFx was a surprising result from this study as there is a low level of JD in the breed's country of origin and also due to a speculated increased resistance to JD in Norwegian red cattle [52]. Norwegian Reds are commonly utilised in breeding programmes to increase herd genetic merit [53]. In the 1990's a large number of dairy cattle were imported to Ireland from continental Europe [16]. The practice of importing cattle from abroad has been associated with increased risk of testing JD positive [29]. It is possible that farms in the present study that utilised Norwegian Reds to improve herd genetic merit may have previously imported cows from abroad, possibly allowing the establishment of JD within the herd, facilitating current transmission to Norwegian Red cows. Indeed it is possible that herds interested in cross breeding and improving herd genetic merit may be more progressive and potentially larger in size further exacerbating the increased odds of testing positive.

\section{Conclusion}

An Ap and Tp of 7.4 and $3.8 \%$, respectively was recorded in this study and no statistically significant production losses were identified although the majority of study farms engaged in high risk management practices for JD transmission. Although the average dairy herd size in Ireland is relatively small, which may be protective against MAP transmission, the abolition of
EU milk quotas is leading to dramatic increases in herd size in Ireland. As this study reiterates the increased risk of JD in larger herds it will be necessary to repeat economic studies to monitor the impact of changing demographics in national herds.

\section{Endnotes \\ ${ }^{1}$ www.animalhealthireland.ie}

\section{Abbreviations}

Ap/Tp: Apparent/True Prevalence; Cl: calving interval; JD: Johne's disease; MAP: Mycobacterium avium subspecies paratuberculosis; MY/MF/MP: milk yield/fat/protein; Se: sensitivity; SCC: somatic cell count; Sp: specificity.

\section{Competing interests}

The authors declare that they have no competing interests.

\section{Authors' contributions}

$\mathrm{RS}, \mathrm{NB}, \mathrm{JOM}$ participated in the conceptual aspect of the work. NB, AK, RS involved in sample collection. All authors provided consultation and coordination. AK \& RS wrote the first draft of the manuscript, with all authors involved in reviewing. All authors read and approved the final manuscript.

\section{Acknowledgements}

This Teagasc research was funded by the Irish Dairy Levy. The authors thank the Irish Cattle Breeding Federation, and the farmers who gave their time to participate in this study.

\section{Author details}

${ }^{1}$ Animal \& Bioscience Research Department, Animal \& Grassland Research and Innovation Centre, Teagasc, Moorepark, Fermoy, Co. Cork, Ireland.

${ }^{2}$ Department of Biological Sciences, Cork Institute of Technology,

Bishopstown, Co. Cork, Ireland.

Received: 26 August 2015 Accepted: 24 February 2016

Published online: 02 March 2016

\section{References}

1. Fourichon C, Seegers H, Bareille N, Beaudeau F. Effects of disease on milk production in the dairy cow: a review. Prev Vet Med. 1999;41(1):1-35.

2. Chi J, VanLeeuwen JA, Weersink A, Keefe GP. Direct production losses and treatment costs from bovine viral diarrhoea virus, bovine leukosis virus, Mycobacterium avium subspecies paratuberculosis, and Neospora caninum. Prev Vet Med. 2002;55(2):137-53.

3. Stott A, Jones G, Humphry R, Gunn G. Financial incentive to control paratuberculosis (Johne's disease) on dairy farms in the United Kingdom. Vet Rec. 2005;156(26):825-31.

4. Ayele WY, Machackova M, Pavlik I. The transmission and impact of paratuberculosis infection in domestic and wild ruminants. Vet Med. 2001; 46(7-8):205-24.

5. Hasonova L, Pavlik I. Economic impact of paratuberculosis in dairy cattle herds: a review. Vet Med. 2006;51(5):193-211.

6. Stabel JR. Johne's Disease: A Hidden Threat. J Dairy Sci. 1998;81(1):283-8.

7. Gilardoni LR, Paolicchi FA, Mundo SL. Bovine paratuberculosis: a review of the advantages and disadvantages of different diagnostic tests. Rev Argent Microbiol. 2012:44:201-15.

8. Olsen I, Sigurðardóttir Ó, Djønne B. Paratuberculosis with special reference to cattle A review. Vet Q. 2002;24(1):12-28.

9. Nielsen SS, Toft N. Ante mortem diagnosis of paratuberculosis: a review of accuracies of ELISA, interferon- $\gamma$ assay and faecal culture techniques. Vet Microbiol. 2008:129(3):217-35.

10. Böttcher J, Gangl A. Mycobacterium avium ssp. paratuberculosis-combined serological testing and classification of individual animals and herds. J Veterinary Med Ser B. 2004;51(10):443-8.

11. Nielsen SS. Danish control programme for bovine paratuberculosis. BCVA 2007;2007:161-8.

12. Raizman EA, Fetrow JP, Wells SJ. Loss of income from cows shedding Mycobacterium avium subspecies paratuberculosis prior to calving 
compared with cows not shedding the organism on two Minnesota dairy farms. J Dairy Sci. 2009;92(10):4929-36.

13. Richardson E, More SJ. Direct and indirect effects of Johne's disease on farm and animal productivity in an Irish dairy herd. Ir Vet J. 2009;62(8):526.

14. Johnson-Ifearulundu YJ, Kaneene JB, Sprecher DJ, Gardiner JC, Lloyd JW. The effect of subclinical Mycobacterium paratuberculosis infection on days open in Michigan, USA, dairy cows. Prev Vet Med. 2000;46(3):171-81.

15. Ott SL, Wells SJ, Wagner BA. Herd-level economic losses associated with Johne's disease on US dairy operations. Prev Vet Med. 1999;40(3):179-92.

16. Barrett DJ, Good M, Hayes M, More SJ. The economic impact of Johne's disease in an Irish dairy herd: A case study. Ir Vet J. 2006;59(5):282.

17. Benedictus G, Dijkhuizen A, Stelwagen J. Economic losses due to paratuberculosis in dairy cattle. Vet Rec. 1987;121(7):142-6.

18. Gonda MG, Chang YM, Shook GE, Collins MT, Kirkpatrick BW. Effect of Mycobacterium paratuberculosis infection on production, reproduction, and health traits in US Holsteins. Prev Vet Med. 2007;80(2-3):103-19.

19. Sorge US, Lissemore K, Godkin A, Hendrick S, Wells S, Kelton D. Associations between paratuberculosis milk ELISA result, milk production, and breed in Canadian dairy cows. J Dairy Sci. 2011;94(2):754-61.

20. McNab WB, Meek AH, Martin SW, Duncan JR. Associations between dairy production indices and lipoarabinomannan enzyme-immunoassay results for paratuberculosis. Can J Vet Res. 1991;55(4):356.

21. Johnson Y, Kaneene J, Gardiner J, Lloyd J, Sprecher D, Coe P. The Effect of Subclinical Mycobacterium paratuberculosis Infection on Milk Production in Michigan Dairy Cows. J Dairy Sci. 2001;84(10):2188-94.

22. Hoogendam K, Richardson E, Mee JF. Paratuberculosis sero-status and milk production, SCC and calving interval in Irish dairy herds. Ir Vet J. 2009;62 Suppl 4:265.

23. Lombard JE, Garry FB, McCluskey BJ, Wagner BA. Risk of removal and effects on milk production associated with paratuberculosis status in dairy cows. J Am Vet Med Assoc. 2005;227(12):1975-81.

24. Dieguez F, Arnaiz I, Sanjuan M, Vilar M, Yus E. Management practices associated with Mycobacterium avium subspecies paratuberculosis infection and the effects of the infection on dairy herds. Vet Rec. 2008;162(19):614-7.

25. Hendrick SH, Duffield TF, Kelton DF, Leslie KE, Lissemore KD, Archambault M. Evaluation of enzyme-linked immunosorbent assays performed on milk and serum samples for detection of paratuberculosis in lactating dairy cows. J Am Vet Med Assoc. 2005;226(3):424-8.

26. Good M, Clegg T, Sheridan H, Yearsely D, O'Brien T, Egan J, et al. Prevalence and distribution of paratuberculosis (Johne's disease) in cattle herds in Ireland. Ir Vet J. 2009;62(9):597.

27. Dillon P. The Irish dairy industry - Planning for 2020. In: Irish national dairy conference: 2011. Ireland: Teagasc; 2011. p. 1-24.

28. Sayers R, Sayers G, Mee JF, Good M, Bermingham ML, Grant J, et al. Implementing biosecurity measures on dairy farms in Ireland. Vet J. 2013;197(2):259-67.

29. Barrett D, Mee J, Mullowney P, Good M, McGrath G, Clegg T, et al. Risk factors associated with Johne's disease test status in dairy herds in Ireland. Vet Rec. 2011;168(15):410-0.

30. Fry MP, Kruze J, Collins MT. Evaluation of four commercial enzyme-linked immunosorbent assays for the diagnosis of bovine paratuberculosis in Chilean dairy herds. J Vet Diagn Investig. 2008;20(3):329-32.

31. Collins MT, Wells SJ, Petrini KR, Collins JE, Schultz RD, Whitlock RH. Evaluation of five antibody detection tests for diagnosis of bovine paratuberculosis. Clin Diagn Lab Immunol. 2005;12(6):685-92.

32. Olori VE, Galesloot PJ. Projection of partial lactation records and calculation of 305-day yields in the Republic of Ireland. Int Bull. 1999;22:149.

33. Berry DP, Shalloo L, Cromie AR, Veerkamp RF, Dillon P, Amer PR, Kearney JF, Evans RD, Wickham B. The economic breeding index: a generation on Technical Report to the Irish Cattle Breeding Federation. 2007, 29-34.

34. Sergeant E. Epitools epidemiological calculators. AusVet Animal Health Services and Australian Biosecurity Cooperative Research Centre for Emerging Infectious Disease. In., vol. 2015. http://epitools.ausvet.com.au. 2015.

35. Garcia A, Shalloo L. Invited review: The economic impact and control of paratuberculosis in cattle. J Dairy Sci. 2015;(98):5019-5039.

36. Benedictus G, Verhoeff J, Schukken Y, Hesselink J. Dutch paratuberculosis programme history, principles and development. Vet Microbiol. 2000;77(3):399-413

37. Kennedy AE, Da Silva AT, Byrne N, Mac Sharry J, Govender R, O'Mahony J, Sayers RG. The single intradermal cervical comparative test interferes with Johne's disease ELISA diagnostics. Front Immunol. 2014;5:564.
38. Lombard JE, Byrem TM, Wagner BA, McCluskey BJ. Comparison of milk and serum enzyme-linked immunosorbent assays for diagnosis of Mycobacterium avium subspecies paratuberculosis infection in dairy cattle. $J$ Vet Diagn Investig. 2006;18(5):448-58.

39. Cooney R, Kazda J, Quinn J, Cook B, Muller K, Monaghan M. Environmental mycobacteria in Ireland as a source of non-specific sensitisation to tuberculins. Ir Vet J. 1997;50(6):370-3.

40. Osterstock JB, Fosgate GT, Norby B, Manning EJ, Collins MT, Roussel AJ. Contribution of environmental mycobacteria to false-positive serum ELISA results for paratuberculosis. J Am Vet Med Assoc. 2007;230(6):896-901.

41. Cashman W, Buckley J, Quigley T, Fanning S, More S, Egan J, Berry D, Grant I, O'Farrell K. Risk factors for the introduction and within-herd transmission of Mycobacterium avium subspecies paratuberculosis (MAP) infection on 59 Irish dairy herds. Ir Vet J. 2008;61(7):464.

42. Kennedy AE, O'Doherty EF, Byrne N, O'Mahony J, Kennedy E, Sayers RG. A survey of management practices on Irish dairy farms with emphasis on risk factors for Johne's disease transmission. Ir Vet J. 2014;67(1):1-11.

43. Vasseur E, Borderas F, Cue R, Lefebvre D, Pellerin D, Rushen J, Wade K, De Passille A. A survey of dairy calf management practices in Canada that affect animal welfare. J Dairy Sci. 2010;93(3):1307-16.

44. Losinger W, Wells S, Garber L, Hurd H, Thomas L. Management factors related to Salmonella shedding by dairy heifers. J Dairy Sci. 1995;78(11):2464-72.

45. Pithua P, Espejo LA, Godden SM, Wells SJ. Is an individual calving pen better than a group calving pen for preventing transmission of Mycobacterium avium subsp paratuberculosis in calves? Results from a field trial. Res Vet Sci. 2013;95(2):398-404.

46. Van Winden S, Stevens K, Guitian J, Mcgowan M. Preliminary findings of a systematic review and expert opinion workshop on biosecurity on cattle farms in the UK. Cattle Pract: J Br Cattle Vet Assoc. 2005;13(2):135-40.

47. C.S.O. Census of Agriculture 2010- Final Results. In. Edited by Office CS. http://www.cso.ie/en/media/csoie/releasespublications/documents/ agriculture/2010/full2010.pdf; 2012

48. New Zealand Dairy Statistics 2011-2012; http://www.dairynz.co.nz/media/ 434165/new_zealand_dairy_statistics_2011-12.pdf. Accessed 10 Jan 2016.

49. de la Rua-Domenech R, Goodchild AT, Vordermeier HM, Hewinson RG, Christiansen $\mathrm{KH}$, Clifton-Hadley RS. Ante mortem diagnosis of tuberculosis in cattle: A review of the tuberculin tests, $y$-interferon assay and other ancillary diagnostic techniques. Res Vet Sci. 2006;81(2):190-210.

50. Maher P, Good M, More S. Trends in cow numbers and culling rate in the Irish cattle population, 2003 to 2006. Ir Vet J. 2008;61(7):455.

51. Shalloo L, Ryan A, French P: Getting ready for Expansion! Lessons from the Greenfield project. In: Proceedings. Teagasc National Dairy Conference. Is Ireland ready for more milk. November 2012, Ireland.

52. Holstad G, Sigurdaroottir O, Storset A, Tharaldsen J, Nyberg O, Schonheit J, Djonne B. Description of the infection status in a Norwegian cattle herd naturally infected by Mycobacterium avium subsp. paratuberculosis. Acta Vet Scand. 2005;46(1-2):45-56.

53. Buckley F, Begley N, Prendiville R, Evans R, Cromie A. Crossbreeding the dairy herd-a real alternative. Ir Grassland Assoc J. 2008:42:5-17.

\section{Submit your next manuscript to BioMed Central and we will help you at every step:}

- We accept pre-submission inquiries

- Our selector tool helps you to find the most relevant journal

- We provide round the clock customer support

- Convenient online submission

- Thorough peer review

- Inclusion in PubMed and all major indexing services

- Maximum visibility for your research

Submit your manuscript at www.biomedcentral.com/submit
Biomed Central 